\title{
Non-leisure time physical activity is an independent predictor of longevity for a Taiwanese elderly population: an eight-year follow-up study
}

Yu-Pei Lin', Ying-Hsiang Huang ${ }^{2}$, Feng-Hwa Lu ${ }^{2,3}$, Jin-Shang Wu ${ }^{2,3}$, Chih-Jen Chang ${ }^{2,3}$ and Yi-Ching Yang ${ }^{2,3^{*}}$

\begin{abstract}
Background: The aim of this study is to determine the relationship between leisure time physical activity (LTPA) and non-leisure time physical activity (NLTPA) on mortality among the elderly in Taiwan.

Methods: This is a prospective observational cohort study. We analyzed the mortality data from a cohort of 876 non-institutionalized community-dwelling men and women aged 65 years or over, who were recruited by stratified clustering random sampling from Tainan city and participated in the 1996 Elderly Medication Survey. Information about activities and other variables were collected by structured interviews at baseline in the participants' home. The Cox proportional hazards model and crude death rate were applied to estimate mortality risk.

Results: Among the 876 participants, 312 died during the follow-up period (1996-2004). In the unadjusted Cox regression model, subjects aged over 75, having difficulty in carrying out activities of daily living (ADLs), a BMI less than 18.5, a history of diabetes mellitus or stroke, without LTPA or being inactive in NLTPA, were found to have a higher risk of eight-year mortality. With the adjustment for age, gender, education level, habitual smoking and drinking, living status, BMI and medical history, the mortality was found to be higher among the sedentary subjects, either defined by lack of LTPA or NLTPA, with the hazard ratio of 1.27 (95\% confidence interval [CI] = 0.97-1.66) and $1.45(95 \% \mathrm{Cl}=1.07-1.97)$, respectively. Furthermore, when both LTPA and NLTPA were put into the model simultaneously, NLTPA ( $H R=1.40 ; 95 \% \mathrm{Cl}=1.03-1.91)$ but not LTPA ( $H R=1.21,95 \% \mathrm{Cl}=0.92-1.59)$ significantly predicted mortality during eight-year follow-up. In addition, subjects who were actively engaged in NLTPA had a lower mortality risk especially in subjects without performing LTPA.
\end{abstract}

Conclusions: NLTPA is an independent predictor of longevity among older people in Taiwan. A physically active lifestyle, especially engaged in NLTPA, is associated with lower mortality risk in the elderly population. We thus suggest that encouraging older people to keep on engaging in customary NLTPA is good for their health.

\section{Background}

Regular physical activity is a modifiable factor for reducing the risks of obesity, cardiovascular disease, hypertension, diabetes, certain cancers, and premature mortality, and all of these benefits have been demonstrated in the elderly [1-8]. Physical activity has been defined as "any bodily movement produced by skeletal

\footnotetext{
* Correspondence: yiching@mail.ncku.edu.tw

${ }^{2}$ Department of Family Medicine, National Cheng Kung University Hospital, Tainan, Taiwan

Full list of author information is available at the end of the article
}

muscle and resulting in energy expenditure" [9]. LTPA is defined as "physical activity performed during exercise, recreation or any time other than those associated with one's regular occupation, housework, or transportation", while NLTPA are those associated with transportation, occupations, and housework [10]. However, most of the related studies focus only on leisure time physical activity (LTPA), and have less emphasis on non-leisure time physical activity (NLTPA), which comprises the majority of physical activity for the elderly [11-16].
C Biomed Central

(C) 2011 Lin et al; licensee BioMed Central Ltd. This is an Open Access article distributed under the terms of the Creative Commons Attribution License (http://creativecommons.org/licenses/by/2.0), which permits unrestricted use, distribution, and reproduction in any medium, provided the original work is properly cited. 
Research shows that NLTPA is the major source of overall physical activity among the elderly. The National Human Activity Pattern Survey (NHAPS), which included representative samples from the United States, revealed that housework related activities contributed $35.2 \%$ of total energy expenditure compared to $5.2 \%$ of leisure time physical activities in subjects aged 65-74 [11]. A 10-year follow up study with 1,042 people aged 65 years or above conducted at Nottingham, the UK, reported that the time spent on housework is four to eleven times as much as that spent on leisure activities [12]. In addition, the prevalence of individuals achieving the recommended levels of physical activity increased 1.3 to 3 -fold after including housework [13,14]. In a large survey of elderly British women, the percentage that reached the recommended levels increased from $21 \%$ to $66.7 \%$ if housework was included [15]. Focusing only on LTPA may thus underestimate the total amount of physical activity and bias the relationship between physical activity and mortality in women, whose NLTPA constitutes $82 \%$ of their daily activity $[17,18]$. Similarly, in the elderly NLTPA is the major source of overall physical activity.

While the benefits of LTPA with regard to elderly mortality are well-documented in the literature [1-8], the effects of NLTPA have not been studied as extensively [12,18-20]. Glass et al. found that NLTPA was associated with a lower mortality rate in a communitydwelling older population [19]. Morgan et al found that NLTPA predicted all-cause mortality over 10 years in British adult aged 65 years or over [12]. Arriet and Russel also found that higher levels of NLTPA were associated with reduced risk of all-cause mortality over a 20 year in non-institutionized U.S adults aged 60-74 [20]. In recent years, more researchers have focused their attention on NLTPA and proposed that the current general emphasis on purposeful, structured, recreational activities may be too narrow [21].

The purpose of this paper was thus to determine the relationship between two types of physical activity, namely NLTPA and LTPA, and the mortality risk of community-dwelling elderly Taiwanese in an eight-year follow-up study.

\section{Methods \\ Subjects}

Tainan city, located in southern Taiwan, comprises seven administrative districts with more than 710,000 residents in 1996 . The sampling scheme was a threestage process that generated a stratified cluster sample of eligible subjects throughout the city [22]. First, areas of the city were grouped into seven strata according to the administrative districts. One area ("li" in Mandarin) was randomly selected from each stratum. Second, all residents aged 65 years or older from each area were selected. In total, there were 1,435 subjects aged 65 years or above were candidates to be included in our study. Third, the selected subjects were informed about the survey by letter, telephone and door-to-door invitation to ask for consent and to arrange a suitable item for the home visits. This survey had received approval from the Institutional Review Board of National Cheng Kung University Hospital, and the investigations were carried out in accordance with the Helsinki Declaration.

\section{Data collection}

First, we collected as much of the data directly from the study subjects as possible. If our study subject had difficulty in communicating or comprehension (such as hearing or cognitive impairment, mild dementia, and so on), we interviewed the primary caregiver, alternatively. At baseline, information was collected through face-toface home interviews by a well-trained pharmacist using a structured questionnaire that included items related to demographic data (e.g., age, sex, education level), living status (living alone or not), lifestyle habits (such as smoking and drinking habits), levels of leisure time and non-leisure time physical activity, medical history (including cancer, stroke, heart disease, diabetes, liver disease, renal disease, pulmonary disease, hypertension, and osteoarthropathy) and daily living activities (including bathing, dressing, using the toilet, moving from a bed to a chair and back, eating and voluntarily controlling urinary and fecal discharge). Body height and weight measurements were obtained using standardized protocols.

\section{Leisure time physical activity assessment}

Physical activity was assessed at the beginning of the follow-up period in 1996. Subjects were asked about the frequency and duration of performing twelve common LTPA in the previous two weeks, which were as follows: calisthenics or tai chi, gardening, walking for pleasure, bicycling, jogging, hiking, aerobic dancing, folk dancing, tennis, swimming, golf, and miscellaneous exercise. The intensity levels were estimated using the compendium of physical activities developed by Ainsworth et al [23]. For each individual, LTPA energy expenditure in METhours per kilogram body weight can be estimated by summing up the energy expenditure of all activities on a weekly basis (MET.hr.wk-1). We divided the subjects into two groups: LTPA non-participants (MET-hour/ week $=0)$ and LTPA participants (MET-hour/week >0).

\section{Non-leisure time physical activity assessment}

An NLTPA questionnaire was used to assess the level of activity with regard to housework and transportation (see Additional file 1). Based on the Physical Activity 
Scale for the Elderly [24], which has been validated for assessments of physical activity in epidemiological studies of older and diverse populations, we adapted a modified scale suitable for elderly Taiwanese subjects, and it had been verified in terms of both expert and content validity. The test-retest reliability after two weeks was 0.99 . In this analysis, subjects who engaged in any activities of NLTPA (either housework or transportation) at least five times per week were classified as part of the "NLTPA active" group, and those who failed to meet this level as the among the "NLTPA inactive" group. The cut-off point to define NLTPA is arbitrary. We refer the ACSM's (American College of Sports Medicine) exercise guidelines for older adults, which recommended the older adults to perform moderate-intensity physical activity at least 5 times/week.

\section{Mortality}

Vital status was verified by matching the subjects' personal identity numbers with the national death registry file obtained from the Department of Health, Taiwan, where all death certificates issued by doctors are sent. Mortality follow-up began on 1 January 1996, and ended on 31 December 2004.

\section{Data analyses}

The SPSS 17.0 software package was used in the statistical analyses. Adjusted and unadjusted Cox analyses were used to estimate mortality risk for the assorted variables. We excluded subjects who had deficits in their ADLs from the adjusted Cox regression model because difficulty in ADLs represents the presence of limitation in physical activity. The crude death rate, calculated in terms of 1,000 people per year, was used to compare the mortality between different levels of physically activity groups.

\section{Results}

A total of 188 of 1,435 registered residents who were selected for the study were no longer living at their previous address. The response rate among the remaining 1,247 subjects was $70.2 \%$ (876 of 1247). Reasons for non-response were "impossible to contact during the three visits" 201(54.2\%); "living in other cities temporarily" $128(34.5 \%)$; "refusal to be interviewed" 25(6.7\%); and "difficulty to be interviewed due to poor health" 17 (4.6\%). In terms of source of information, 834(95.2\%) interviews were responded by the study subjects and the other $42(4.8 \%)$ were by primary caregivers. We compared sociodemographic data between responders $(\mathrm{n}=$ $876)$ and non-responders $(\mathrm{n}=559)$. Table 1 shows that responding was not associated with gender or education level. However, non-responders had a statistically significant higher average age and higher prevalence of widow/widower status than the responder group.
Table 1 Comparison of sociodemographic data between responders and non-responders in the Elderly Medication Cohort Follow-up Study in Tainan City, Taiwan, 19962004

\begin{tabular}{|c|c|c|c|}
\hline & Responders(\%) & Nonresponders(\%) & \\
\hline Variables & $(\mathrm{N}=876)$ & $(\mathrm{N}=559)$ & P Value $^{a}$ \\
\hline Age, years & $72 \pm 6.1$ & $73.8 \pm 7.1$ & $<.005^{b}$ \\
\hline Age group & & & $<.05$ \\
\hline $65-69$ & $330(37.7)$ & $186(33.3)$ & \\
\hline $70-74$ & 279 (31.8) & $152(27.2)$ & \\
\hline $75-79$ & $148(16.9)$ & $108(19.3)$ & \\
\hline$\geqq 80$ & 119 (14.6) & $113(20.2)$ & \\
\hline Sex & & & $N S^{c}$ \\
\hline Men & $477(54.5)$ & $294(52.6)$ & \\
\hline Women & $399(45.5)$ & $265(47.3)$ & \\
\hline Education level & & & NS \\
\hline Illiterate & 367 (41.9) & $223(39.4)$ & \\
\hline Elementary & $313(35.7)$ & $195(34.9)$ & \\
\hline Junior high & $79(9.0)$ & $52(9.3)$ & \\
\hline Senior high & $67(7.6)$ & $56(10.0)$ & \\
\hline$\geqq$ college & $50(6.7)$ & $33(5.9)$ & \\
\hline \multicolumn{4}{|l|}{ Marital } \\
\hline Married & $549(62.7)$ & $288(51.5)$ & \\
\hline Widow/widower & $206(23.5)$ & $166(29.9)$ & \\
\hline Divorced & $21(2.4)$ & $10(1.8)$ & \\
\hline Unmarried & $100(11.4)$ & $95(17.0)$ & \\
\hline Occupation & & & NS \\
\hline Yes & $182(32.2)$ & $225(40.3)$ & \\
\hline No & 594 (67.8) & $334(59.7)$ & \\
\hline
\end{tabular}

${ }^{a}$ Chi-square test between responders and nonresponders.

${ }^{\mathrm{b}} \mathrm{t}$ test.

${ }^{c} \mathrm{NS}=$ no significant at $\mathrm{p}$ value $>.05$.

Table 2 demonstrates the comparison of characteristics of the participants across LTPA and NLTPA groups. We found that subjects aged under 75 with a higher education level, normal weight (BMI between 18.5 and $30 \mathrm{Kg} / \mathrm{m}^{2}$ ) and without history of stroke were more active in LTPA. Those aged under 75, living alone, normal weighted, without ADLs deficit and no history of stroke or arthritis had a higher percentage that engaged in NLTPA.

Among the 876 participants, 312 died during the follow-up period (1996-2004). Table3 shows the univariate analysis of all-cause mortality on baseline variables. Subjects who did not participate in LTPA (0 MET-hour/ week) had a higher mortality rate than those who were regular LTPA participants $(\mathrm{HR}=1.56 ; 95 \% \mathrm{CI}=1.24$ 1.96). Those who were less engaged in NLTPA, that is performed NLTPA less than five times per week, had significantly higher mortality risk than their counterparts who regularly engaged in NLTPA $(\mathrm{HR}=2.19 ; 95 \% \mathrm{CI}=$ 1.73-2.79). Higher mortality rates were also observed among those subjects who had any difficulty in ADLs 
Table 2 Comparison of baseline variables in LTPA and NLTPA groups in the Elderly Medication Cohort Follow-up Study in Tainan City, 1996-2004

\begin{tabular}{|c|c|c|c|c|c|c|}
\hline & & LTPA $^{1}$ & & & NLTPA $^{2}$ & \\
\hline & $\begin{array}{l}\text { Participants } \\
(n=593)\end{array}$ & $\begin{array}{c}\text { Non-participants } \\
(n=283)\end{array}$ & $\mathrm{P}^{3}$ & $\begin{array}{c}\text { Active } \\
(n=697)\end{array}$ & $\begin{array}{l}\text { Inactive } \\
(\mathrm{n}=179)\end{array}$ & $\mathrm{P}^{3}$ \\
\hline Age(y/o) & & & $<0.01$ & & & $<0.01$ \\
\hline $65-75$ & 68.5 & 27.1 & & 69.4 & 40.8 & \\
\hline $76-80$ & 17.0 & 32.2 & & 15.2 & 24.0 & \\
\hline$\geqq 81$ & 14.5 & 29.7 & & 15.4 & 35.2 & \\
\hline Sex & & & 0.19 & & & 0.94 \\
\hline Male & 56.0 & 51.2 & & 54.5 & 54.2 & \\
\hline Female & 44.0 & 48.8 & & 45.5 & 45.8 & \\
\hline Education level & & & $<0.01$ & & & 0.22 \\
\hline Under elementary school & 27.0 & 18.4 & & 25.1 & 20.7 & \\
\hline Junior high school and above & 73.0 & 81.6 & & 74.9 & 79.3 & \\
\hline Smoking status & & & 0.56 & & & 0.09 \\
\hline Never/ex-smokers & 76.7 & 74.9 & & 74.9 & 81.0 & \\
\hline Current smokers & 23.3 & 25.1 & & 25.1 & 19.0 & \\
\hline Drinking habit & & & 0.06 & & & 0.04 \\
\hline$<3$ times per week & 92.9 & 96.1 & & 93.1 & 97.2 & \\
\hline$\geqq 3$ times per week & 7.1 & 3.9 & & 6.9 & 2.8 & \\
\hline Living alone & & & 0.13 & & & $<0.01$ \\
\hline No & 90.6 & 93.6 & & 89.8 & 98.3 & \\
\hline Yes & 9.4 & 6.4 & & 10.2 & 1.7 & \\
\hline LTPA & & & & & & $<0.01$ \\
\hline Participants & - & - & - & 75.5 & 37.4 & \\
\hline Non-participants & - & - & - & 24.5 & 62.6 & \\
\hline NLTPA & & & $<0.01$ & & & \\
\hline Active & 88.7 & 60.4 & & - & - & \\
\hline Inactive & 11.3 & 39.6 & & - & - & \\
\hline $\mathrm{BMI}\left(\mathrm{Kg} / \mathrm{m}^{2}\right)$ & & & $<0.01$ & & & $<0.01$ \\
\hline $18.5 \leqq \mathrm{BMI} \leqq 30$ & 84.5 & 63.6 & & 83.2 & 56.4 & \\
\hline $\mathrm{BMI}<18.5$ & 12.8 & 33.2 & & 13.6 & 41.9 & \\
\hline $\mathrm{BMI}<30$ & 2.7 & 3.2 & & 3.2 & 1.7 & \\
\hline$A D L$ & & & $<0.01$ & & & $<0.01$ \\
\hline Without difficulty & 99.2 & 78.1 & & 99.7 & 63.7 & \\
\hline With difficulty & 0.8 & 21.9 & & 0.3 & 36.3 & \\
\hline Cancer & & & 0.52 & & & 0.13 \\
\hline No & 98.5 & 99.3 & & 98.4 & 100 & \\
\hline Yes & 1.5 & 0.7 & & 1.6 & 0 & \\
\hline Hypertension & & & 0.39 & & & 0.23 \\
\hline No & 68.1 & 71.0 & & 70.0 & 65.4 & \\
\hline Yes & 31.9 & 29.0 & & 30.0 & 34.6 & \\
\hline Diabetes Mellitus & & & 0.31 & & & 0.97 \\
\hline No & 87.0 & 89.4 & & 87.8 & 87.7 & \\
\hline Yes & 13.0 & 10.6 & & 12.2 & 12.3 & \\
\hline Stroke & & & $<0.01$ & & & $<0.01$ \\
\hline No & 96.0 & 89.4 & & 97.4 & 79.9 & \\
\hline Yes & 4.0 & 10.6 & & 2.6 & 20.1 & \\
\hline Heart Disease & & & 0.11 & & & 0.82 \\
\hline No & 85.0 & 88.3 & & 85.9 & 86.6 & \\
\hline Yes & 15.0 & 11.7 & & 14.1 & 13.4 & \\
\hline Pulmonary disease & & & 0.01 & & & 0.56 \\
\hline No & 94.6 & 90.1 & & 93.4 & 92.2 & \\
\hline
\end{tabular}


Table 2 Comparison of baseline variables in LTPA and NLTPA groups in the Elderly Medication Cohort Follow-up Study in Tainan City, 1996-2004 (Continued)

\begin{tabular}{|c|c|c|c|c|c|c|}
\hline Yes & 5.4 & 9.9 & & 6.6 & 7.8 & \\
\hline Liver disease & & & 0.20 & & & 0.13 \\
\hline No & 93.6 & 95.8 & & 93.6 & 96.6 & \\
\hline Yes & 6.4 & 4.2 & & 6.3 & 3.4 & \\
\hline Renal disease & & & 0.17 & & & 0.46 \\
\hline No & 97.5 & 95.8 & & 96.7 & 97.8 & \\
\hline Yes & 2.5 & 4.2 & & 3.3 & 2.2 & \\
\hline Arthritis/osteoporosis & & & 0.01 & & & $<0.01$ \\
\hline No & 63.2 & 53.4 & & 62.6 & 50.3 & \\
\hline Yes & 36.8 & 46.6 & & 37.4 & 49.7 & \\
\hline
\end{tabular}

${ }^{1}$ LTPA $=$ leisure time physical activity

${ }^{2}$ NLTPA $=$ non-leisure time physical activity

${ }^{3}$ chi-square test for categorical variables

$(\mathrm{HR}=2.38 ; 95 \% \mathrm{CI}=1.71-3.32)$, BMI less than $18.5(\mathrm{HR}$ $=1.73$; $95 \% \mathrm{CI}=1.34-2.23)$, diabetes mellitus $(\mathrm{HR}=1.52$; $95 \% \mathrm{CI}=1.12-2.06)$ or stroke $(\mathrm{HR}=1.91 ; 95 \% \mathrm{CI}=1.32$ 2.77) at baseline. Table4 shows the adjusted HR for allcause mortality after inclusion of either LTPA (model 1) or NLTPA (model 2) separately, and both types of physical activities together (model 3). All three models were adjusted for other 16 covariates such as age, gender, level of education, habitual smoking and drinking, living status, BMI, and medical history including cancer, stroke, heart disease, diabetes, liver disease, renal disease, pulmonary disease, hypertension, and osteoarthropathy. Those subjects who were inactive in LTPA or NLTPA had higher mortality rates with the HR of 1.27 (95\% CI = $0.97-1.66)$ and $1.45(95 \% \mathrm{CI}=1.07-1.97)$, respectively, in models 1 and 2. However, if both NLTPA and LTPA were put into the model simultaneously (model 3 ), NLTPA but not LTPA could significantly predict mortality. That is, with the control of LTPA and other covariates, subjects who engaged in less NLTPA had a higher mortality rate than their counterparts with the HR of 1.40 (95\% CI $=1.03-1.91)$. To measure the predictive capacity (discriminatory power) of different Cox models, we use the concordance (C-) index (25). There are similar c-index within three models with the value of 0.49 $(95 \% \mathrm{CI}=0.37-0.61), 0.49(95 \% \mathrm{CI}=0.37-0.61)$ and 0.48 (95\%CI $=0.37-0.60)$ in model 1,2 , and 3 , respectively.

We further explored the interaction between LTPA and NLTPA on mortality by comparing hazard ratios of inactive vs active NLTPA groups with different level of LTPA. The results demonstrate that the NLTPA inactive group had a higher mortality risk in both LTPA participant and non-participant groups but the difference is slightly prominent in LTPA non-participant group. The direction is the same and the difference of the effect sizes of NLTPA in the two LTPA strata is not different from a statistically point of view (data not shown).

\section{Discussion}

The main finding of our study is that NLTPA is independently associated with lower mortality risk among elderly Taiwanese, even after adjusting for age, gender, educational level, smoking and drinking habits, living status, medical history, BMI and LTPA. Subjects who engaged in more NLTPA had lower mortality risk especially in the less LTPA group. In our study, NLTPA can predict the survival of older people, and its predictive power was no less than that of LTPA.

Our results are consistent with three cohort studies which suggest that NLTPA is independently associated with lower all-cause mortality among the elderly $[12,19,20]$. In the United States, Glass et al. conducted a 13-year study on elderly subjects in New Heaven which showed that engagement in productive activities, such as gardening, preparing meals, and shopping, could reduce the mortality risk as much as fitness activities did with adjustment of sociodemographic variables, functional disability, and medical history[19]. Morgan et al. also demonstrated a positive influence of customary activities, predominantly NLTPA (including indoor and outdoor housework, shopping, purposeful walking and so on) on 10-year survival among British subjects aged 65 years or over[12]. Arrieta and Russell estimated that mortality risk reductions were $34 \%$ and $38 \%$ for moderate and high NLTPA respectively, compared with low NLTPA in person aged 60-74 over a 20 -year period[20]. Arrieta and Russell's study was derived from the National Health and Nutrition Examination Survey (NHANES I, 1971-1975) and its Epidemiologic Followup Study NHEFS, a large, nationally representative sample of non-institutionalized U.S. adults aged 35-74 at baseline.

Although the exact mechanisms relating NLTPA to longevity are not well known, several hypotheses have been suggested, and psychosocial pathways are thought 
Table 3 Univariate analysis of mortality risk on baseline variables in the Elderly Medication Cohort Follow-up Study in Tainan City, Taiwan, 1996-2004

\begin{tabular}{|c|c|c|c|c|c|}
\hline variables & & Deaths/persons ${ }^{a}$ & No. of person-year & $\begin{array}{l}\text { Death rate } \\
\text { (per } 1,000 \text { person-year) }\end{array}$ & $\mathrm{HR}(95 \% \mathrm{Cl})$ \\
\hline \multirow[t]{3}{*}{ Age $(y / o)$} & $65-75$ & $86 / 557$ & 4641 & 18.5 & 1 \\
\hline & $76-80$ & $96 / 149$ & 1015 & 94.6 & $5.5(4.1-7.4)$ \\
\hline & $\geqq 81$ & $129 / 170$ & 1127 & 114.5 & $6.7(5.1-8.9)$ \\
\hline \multirow[t]{2}{*}{ Sex } & Men & $179 / 477$ & 3652 & 49.0 & 1 \\
\hline & Women & $132 / 399$ & 3131 & 42.2 & $0.9(0.7-1.1)$ \\
\hline \multirow[t]{2}{*}{ Educational } & Under elementary school & $67 / 212$ & 1691 & 39.6 & 1 \\
\hline & Junior high school and above & $244 / 664$ & 5092 & 47.9 & $1.2(0.9-1.6)$ \\
\hline \multirow[t]{2}{*}{ Smoking } & Never/ex-smokers & $234 / 667$ & 5167 & 45.3 & 1 \\
\hline & Current smokers & $77 / 209$ & 1616 & 47.7 & $1.0(0.7-1.2)$ \\
\hline \multirow[t]{2}{*}{ Drinking habit } & $<3$ times/week & $293 / 823$ & 6355 & 46.1 & 1 \\
\hline & $\geqq 3$ times/week & $18 / 53$ & 428 & 42.1 & $0.9(0.6-1.5)$ \\
\hline \multirow[t]{2}{*}{ Living alone } & No & $281 / 802$ & 6365 & 44.2 & 1 \\
\hline & Yes & $30 / 74$ & 558 & 53.8 & $1.2(0.8-1.8)$ \\
\hline \multirow[t]{2}{*}{ ADLs } & Without difficulty & $271 / 809$ & 6365 & 42.6 & 1 \\
\hline & With difficulty & $40 / 67$ & 418 & 95.7 & $2.4(1.7-3.3)$ \\
\hline \multirow[t]{2}{*}{ LTPA } & Participants & $187 / 593$ & 4730 & 39.5 & 1 \\
\hline & Non-participants & $124 / 283$ & 2053 & 60.4 & $1.6(1.2-2.0)$ \\
\hline \multirow[t]{2}{*}{ NLTPA } & Active & 213/697 & 5567 & 38.3 & 1 \\
\hline & Inactive & $98 / 179$ & 1216 & 80.6 & $2.2(1.7-2.8)$ \\
\hline \multirow[t]{3}{*}{ BMI } & $18.5 \leqq \mathrm{BMI} \leqq 30$ & $220 / 681$ & 5381 & 40.9 & 1 \\
\hline & $\mathrm{BMI}<18.5$ & $82 / 170$ & 1192 & 68.8 & $1.7(1.3-2.2)$ \\
\hline & $\mathrm{BMI}>30$ & $9 / 25$ & 210 & 42.9 & $1.0(0.5-2.0)$ \\
\hline \multirow[t]{2}{*}{ Cancer } & No & $305 / 865$ & 6712 & 45.4 & 1 \\
\hline & Yes & $6 / 11$ & 71 & 84.5 & $1.9(0.9-4.3)$ \\
\hline \multirow[t]{2}{*}{ Hypertension } & No & $204 / 605$ & 4696 & 43.4 & 1 \\
\hline & Yes & $107 / 271$ & 2087 & 51.3 & $1.2(0.9-1.5)$ \\
\hline \multirow[t]{2}{*}{ Diabetes mellitus } & No & $261 / 769$ & 6012 & 43.4 & 1 \\
\hline & Yes & $50 / 107$ & 771 & 64.9 & $1.5(1.1-2.1)$ \\
\hline \multirow[t]{2}{*}{ Stroke } & No & $280 / 822$ & 6401 & 43.7 & 1 \\
\hline & Yes & $31 / 54$ & 382 & 81.2 & $1.9(1.3-2.8)$ \\
\hline \multirow[t]{2}{*}{ Heart disease } & No & $262 / 754$ & 5840 & 44.9 & 1 \\
\hline & Yes & $49 / 122$ & 943 & 52.0 & $1.2(0.9-1.6)$ \\
\hline \multirow[t]{2}{*}{ Pulmonary disease } & No & 289/816 & 6315 & 45.8 & 1 \\
\hline & Yes & $22 / 60$ & 468 & 47.0 & $1.0(0.7-1.6)$ \\
\hline \multirow[t]{2}{*}{ Liver disease } & No & $287 / 826$ & 6409 & 44.8 & 1 \\
\hline & Yes & $24 / 50$ & 374 & 64.2 & $1.4(1.0-2.2)$ \\
\hline \multirow[t]{2}{*}{ Renal disease } & No & $300 / 849$ & 6571 & 45.7 & 1 \\
\hline & Yes & $11 / 27$ & 212 & 51.9 & $1.1(0.6-2.1)$ \\
\hline \multirow[t]{2}{*}{ Arthritis/osteoporosis } & No & $187 / 526$ & 4069 & 46.0 & 1 \\
\hline & Yes & $124 / 350$ & 2714 & 45.7 & $1.0(0.8-1.3)$ \\
\hline
\end{tabular}

a number of persons at baseline

HR: hazard ratio, ADLs: Activities of daily living, LTPA: leisure time physical activity, NLTPA: non-leisure time physical activity.

to be in operation in addition to direct physical functioning. The psychological effects of NLTPA, such as the maintenance of normal mental states, distraction from negative emotions, and a sense of self-mastery, are proposed to have a positive health impact that goes beyond the benefit of fitness[19,26]. Engagement in social and productive activities may enhance the sense of having a meaningful social role, which then promotes a feeling of self-efficacy and social support. In addition, purposeful social roles have been found to be associated with decreased mortality in later life[27,28]. Secondly, increasing evidence suggests that total energy expenditure through any activity, rather than a specific level of intensity, may confer a survival advantage in older 
Table 4 The adjusted hazard ratio for all-cause mortality for sedentary versus active subjects in the Elderly Medication Cohort Follow-up Study in Tainan, Taiwan, 1996-2004

\begin{tabular}{lccc}
\hline & Model $\mathbf{1}$ & Model $\mathbf{2}$ & Model $\mathbf{3}$ \\
\cline { 2 - 4 } Physical activities & HR(95\%Cl) & HR(95\%Cl) & HR(95\%Cl) \\
\hline LTPA & & - & $1.21(0.92-1.59)$ \\
$\quad$ Non-participants vs. participants & $1.27(0.97-1.66)$ & & $1.40(1.03-1.91)$ \\
NLTPA & & $1.45(1.07-1.97)$ & 0.48 \\
$\quad$ Inactive vs. active & - & 0.49 & 0.49 \\
C statistic $^{\mathrm{a}}$ & &
\end{tabular}

67 participants with difficulty in ADLs were excluded in multiple-adjusted Cox model.

Model 1: include LTPA and other 16 covariates (age, gender, level of education, habitual smoking and drinking, living status, BMI, cancer, stroke, heart disease, diabetes, liver disease, renal disease, pulmonary disease, hypertension, and osteoarthropathy).

Model 2: include NLTPA and other 16 covariates.

Model 3: include LTPA, NLTPA and 16 covariates.

adults $[1,17,29]$. For example, Manni et al. showed that community-dwelling older adults experienced a $32 \%$ lower risk of mortality for every $287 \mathrm{kcal} /$ day in free-living activity energy expenditure[1]. Short bouts of activities, like NLTPA, can be achieved easily by most elderly people. Finally, the beneficial effects of doing housework may be similar to occupational therapy, which can prevent disability and promote quality-of-life in older adults [30].

Because the content of NLTPA is culturally sensitive, research on different ethnic groups is necessary. For example, washing clothes by hand is a common activity for the elderly in our study, but is less common in the West. Previous studies provide tentative evidence for a link between NLTPA and elderly longevity among British and American subjects[12,19]. This study has examined the effects of productive and transportation activities on the mortality risk among Taiwanese elderly, and the results corroborate the earlier findings that increased physical activity, including NLTPA, can decrease the mortality rate in the elderly.

There are several limitations associated with this observational prospective study that warrant consideration. First, there is a potential non-response bias, since the non-responders were older and had a higher prevalence of widow/widower status, and also might be expected to have a higher mortality rate and lower participation in NLTPA and LTPA. Therefore, our results might under-estimate the negative association between NLTPA and mortality in this relatively younger elderly population. Second, some information bias might be inevitable when communication problems occurred in the interviews, perhaps due to hearing or cognitive impairment, which might lead to a non-differentiated misclassification of our data collection. Such problems may have underestimated the real excess risk. Third, we only semi-quantify the amount of NLTPA by frequency of activities, and thus results from this might not be very precise. If additional components of NLTPA, such as duration or amount, are available, the associations between activity and mortality might be more apparent. Further, the information about physical activities was collected for only the two weeks before the interview, and therefore misclassification might occur if the subjects had recently changed their lifestyle or health status. However, such misclassifications may weaken the apparent survival advantage of physical activities, so the real benefits will be more significant than seen in the present analysis. Since the residual confounders cannot be completely eliminated by multiple risk factors adjustments, the results of this study are not sufficient to infer causal relation between survival and NLTPA/LTPA. Finally, three Cox models failed to provide a good discriminatory power with a low $\mathrm{C}$ statistic-index. This may be due to the relatively small sample size and other unmeasured mortality risk factors.

The strengths of our study include that we provided a simple and useful culture-sensitive questionnaire to predict eight-year mortality of elderly Taiwanese subjects by level of NLTPA. The six-item questionnaire can be applied in community-based screening programs and identify the highest risk group among sedentary elderly who are engaged in neither NLTPA nor LTPA. Furthermore, all our data were collected by a qualified interviewer, and this minimized the measurement bias.

Our findings have several important implications. In research, the unique relationships between different types of physical activity and mortality underscore the necessity of including multiple domains of activity in epidemiologic studies. In health policy, we can identify the people in the greatest need of intervention among the sedentary elderly. According to the Taiwan National Health Interview Survey, up to $51.4 \%$ of elderly men and $42.2 \%$ of elderly women never exercise regularly [31]. As a public health priority, we should categorize those individuals who do not engage in NLTPA among the irregular exercise group as a high-risk group of interest for intervention. In practice, healthcare 
professionals might also recommend a broader range of activities for older people, and encourage them to keep engaging in housework if they already do so. However, in Taiwanese social convention, it is not considered filial if children allow their elderly parents to do housework. We thus propose that the public health messages related to physical activity in this context must emphasize a broader range of activities for older people.

\section{Conclusions}

This study suggests that NLTPA is independently associated with lower mortality risk among the elderly. A physically active lifestyle, engaging in customary NLTPA is good for longevity among the elderly.

\section{Additional material}

Additional File: Appendix 1 shows the questionnaire used to assess the level of non-leisure time physical activity.

\section{Acknowledgements}

This research was supported by Department of Health, Executive Yuan, Republic of China. We would like to acknowledge Dr Shout-Cheng She at Kaohsiung Municipal Ming-Shen Hospital for support throughout this study and Professor Jung-Der Wang for critical advice on this manuscript. We also thank all the subjects who agreed to participate in this study.

\section{Author details}

${ }^{1}$ Department of Family Medicine, Kaohsiung Municipal Min-Shen Hospital, Kaohsiung, Taiwan. ${ }^{2}$ Department of Family Medicine, National Cheng Kung University Hospital, Tainan, Taiwan. ${ }^{3}$ Department of Medicine, College of Medicine, National Cheng Kung University, Tainan, Taiwan.

\section{Authors' contributions}

YPL performed study design, statistical analyses, interpreted results and drafted the manuscript. FHL contributed to designing the study and interpreting results. $\mathrm{YHH}, \mathrm{JSH}$, and CJC participated in interpreting results and technical support. YCY participated in the study design, statistical analysis, interpretation of data and helped to draft the manuscription. All authors read and approved the final manuscript.

\section{Competing interests}

The authors declare that they have no competing interests.

Received: 5 September 2010 Accepted: 3 June 2011

Published: 3 June 2011

\section{References}

1. Manini TM, Everhart JE, Patel KV, Schoeller DA, Colbert LH, Visser M, Tylavsky F, Bauer DC, Goodpaster BH, Harris TB: Daily activity energy expenditure and mortality among older adults. JAMA 2006, 296:171-179.

2. Hakim AA, Petrovitch H, Burchfiel CM, Ross GW, Rodriguez BL, White LR, Yano K, Curb JD, Abbott RD: Effects of walking on mortality among nonsmoking retired men. N Engl J Med 1998, 338:94-99.

3. Bijnen FC, Caspersen CJ, Feskens EJ, Saris WH, Mosterd WL, Kromhout D: Physical activity and 10-year mortality from cardiovascular diseases and all causes: the Zutphen Elderly Study. Arch Intern Med 1998, 158:1499-1505.

4. Stessman J, Maaravi Y, Hammerman-Rozenberg R, Cohen A: The effects of physical activity on mortality in the Jerusalem 70 -year-olds longitudinal study. J Am Geriatr Soc 2000, 48:499-504.

5. Brach JS, Simonsick EM, Kritchevsky S, Yaffe K, Newman AB: The association between physical function and lifestyle activity and exercise in the health, aging and body composition study. J Am Geriatr Soc 2004, 52:502-509.

6. Sundquist K, Qvist J, Sundquist J, Johansson SE: Frequent and occasional physical activity in the elderly: a 12-year follow-up study of mortality. Am J Prev Med 2004, 27:22-27.

7. Gregg EW, Cauley JA, Stone K, Thompson TJ, Bauer DC, Cummings SR, Ensrud KE: Relationship of changes in physical activity and mortality among older women. JAMA 2003, 289:2379-2386.

8. US Department of Health and Human Services: Physical activity and health: report of the Surgeon General. Atlanta, GA: US Department of Health and Human Services, CDC; 1996.

9. Caspersen CJ, Powell KE, Christenson GM: Physical activity, exercise, and physical fitness: definitions and distinctions for health-related research. Public Health Rep 1985, 100:126-131.

10. Kandula NR, Lauderdale DS: Leisure time, non-leisure time, and occupational physical activity in Asian Americans. Ann Epidemio 2005, 15:257-265.

11. Dong L, Block G, Mandel S: Activities contributing to total energy expenditure in the United States: Results from the NHAPS Study. Int J Behav Nutr Phys Act 2009, 1:4.

12. Morgan K, Clarke D: Customary physical activity and survival in later life: a study in Nottingham, UK. J Epidemiol Community Health 1997, 51:490-493.

13. Stamatakis $E$, Hillsdon M, Primatesta P: Domestic physical activity in relationship to multiple CVD risk factors. Am J Prev Med 2007, 32:320-327.

14. Phongsavan P, Merom D, Marshall A, Bauman A: Estimating physical activity level: the role of domestic activities. J Epidemiol Community Health 2004, 58:466-467.

15. Lawlor DA, Taylor M, Bedford C, Ebrahim S: Is housework good for health? Levels of physical activity and factors associated with activity in elderly women. Results from the British Women's Heart and Health Study. J Epidemiol Community Health 2002, 56:473-478.

16. Jones DA, Ainsworth BE, Croft JB, Macera CA, Lloyd EE, Yusuf HR: Moderate leisure-time physical activity: who is meeting the public health recommendations? A national cross-sectional study. Arch Fam Med 1998, 7:285-289

17. Weller I, Corey P: The impact of excluding non-leisure expenditure on the relationship between physical activity and mortality in women. Epidemiology 1998, 9:632-635

18. Villeneuve PJ, Morrison HI, Craig CL, Schaubel DE: Physical activity, physical fitness, and risk of dying. Epidemiology 1998, 9:626-631.

19. Glass TA, de Leon CM, Marottoli RA, Berkman LF: Population based study of social and productive activities as predictors of survival among elderly Americans. BMJ 1999, 319:478-483.

20. Arrieta A, Russell LB: Effects of leisure and non-leisure physical activity on mortality in U.S. adults over two decades. Ann Epidemiol 2008, 18:889-895.

21. Csizmadi I, Robson PJ, Neilson HK: Re: "Influence of exercise, walking, cycling, and overall nonexercise physical activity on mortality in Chinese women". Am J Epidemiol 2007, 166:1355-1356

22. Lu FH, Tang SJ, Wu JS, Yang YC, Chang CJ: Hypertension in elderly persons: its prevalence and associated cardiovascular risk factors in Tainan city, southern Taiwan. J Gerontol Med Sci 2000, 55A:M463-M468.

23. Ainsworth BE, Haskell WL, Leon AS, Jacobs DR Jr, Montoye HJ, Sallis JF, Paffenbarger RS Jr: Compendium of physical activities: classification of energy costs of human physical activities. Med. Sci Sports Exerc 1993, 25:71-80.

24. Washburn RA, Smith KW, Jette AM, Janney CA: The Physical Activity Scale for the Elderly (PASE): development and evaluation. J Clin Epidemiol 1993, 46:153-162.

25. Harrell FE Jr, Lee KL, Mark DB: Multivariable prognostic models: issues in developing models, evaluating assumptions and adequac.

26. Morgan K, Dalleosso H, Bassey EJ, Ebrahim S, Fentem PH, Aire THD: Customary physical activity, psychological wellbeing, and successful ageing. Ageing Society 1991, 11:399-415.

27. Wihelmson K, Allebeck P, Berg S, Steen B: Mortality in three cohorts of 70year olds: the impact of social factors and health. Aging Clin. Exp Res 2002, 14:143-151.

28. Adelmann PK: Multiple roles and psychological well-being in a national sample of older adults. J Gerontol Soc Sci 1994, 49:S277-S285.

29. Pate RR, Pratt M, Blair SN, Haskell WL, Macera CA, Bouchard C, Buchner D, Ettinger W, Heath GW, King AC, Kriska A, Leon AS, Marcus BH, Morris J, 
Paffenbarger RS, Patrick K, Pollock ML, Rippe JM, Sallis J, Wilmore JH: Physical activity and public health. A recommendation from the Centers for Disease Control and Prevention and the American College of Sports Medicine. JAMA 1995, 273:402-407.

30. Clark F, Azen SP, Zemke R, Jackson J, Carlson M, Mandel D, Hay J,

Josephson K, Cherry B, Hessel C, Palmer J, Lipson L: Occupational therapy for independent-living older adults: a randomized controlled trial. JAMA 1997, 278:1321-1326.

31. Hsu CC, Hsu HM, Shu CC, Shih YT, Tai TY: Factors contributing to health behaviors among the elderly in Taiwan. Taiwan J Public Health 2003, 22:441-452.

\section{Pre-publication history}

The pre-publication history for this paper can be accessed here: http://www.biomedcentral.com/1471-2458/11/428/prepub

doi:10.1186/1471-2458-11-428

Cite this article as: Lin et al:: Non-leisure time physical activity is an independent predictor of longevity for a Taiwanese elderly population: an eight-year follow-up study. BMC Public Health 2011 11:428.

\section{Submit your next manuscript to BioMed Central} and take full advantage of:

- Convenient online submission

- Thorough peer review

- No space constraints or color figure charges

- Immediate publication on acceptance

- Inclusion in PubMed, CAS, Scopus and Google Scholar

- Research which is freely available for redistribution

Submit your manuscript at www.biomedcentral.com/submit 